\title{
Sister Mary Joseph's nodule
}

\author{
A Erlank, MB ChB \\ C Ackermann, MB ChB, MMed Rad (Diag), \\ MRCS (UK) \\ P J Greyling, $M B$ ChB \\ Department of Radiology, Stellenbosch University and Tygerberg \\ Academic Hospital
}

Cutaneous metastases localised to the umbilicus are named 'Sister Mary Joseph's nodules'. Sister Mary Joseph, who was the superintendent nurse and surgical assistant of Dr William Mayo at St. Mayo Hospital from 1856 to 1939, was the first to note the link between umbilical nodules and intra-abdominal malignancies. Metastases to the umbilicus are uncommon and represent only $10 \%$ of all secondary tumours which have spread to the skin. This umbilical nodule usually represents a poor prognosis. ${ }^{1}$ Umbilical neoplastic nodules may be due to a primary tumour in $38 \%$ of cases, to endometriosis in $32 \%$ of individuals and in $30 \%$ may actually be secondary tumour deposits from a primary tumour elsewhere. In the case of metastases the source of the primary tumour is usually the gastro-intestinal (35-65\%) or genito-urinary (12-35\%) tract. ${ }^{3}$ This case demonstrates the presence of a large Sister Mary Joseph's nodule in a 16-year-old female patient who presented with a

\section{Neuroradiology workshop}

Chris Hani Baragwanath Hospital hosted a Neuroradiology Workshop from 24 to 27 July organised by General Electric. This was facilitated by the visit of Dr Shawn Halpin, a neuroradiologist from Cardiff University; and Dr Azim Celik, a physicist and GE advanced application specialist. The workshop was attended by the radiology and radiography staff of $\mathrm{CHBH}$.

Lectures and case quizzes were held in the morning, and hands-on advanced MR training was given in the afternoons. This was well facilitated by Dr Celik. MR spectroscopy, tensor imaging, and special MRA techniques were practised.

Dr Shawn Halpin is an experienced neuroradiologist who trained in London. He has published numerous articles in renowned international radiology and neurology journals, has contributed many chapters to books, and most of all is friendly and down-to-earth.

Dr. Azim Celik is a PhD in physics. He trained in the US, and is now based in Turkey. He has a deep understanding of MR physics - quite mind-boggling. He has also published in international radiology journals, where his main interest is working on new sequences.

The format worked very successfully as the knowledge was garnered first hand, in our environment, and with our patients and machine. This

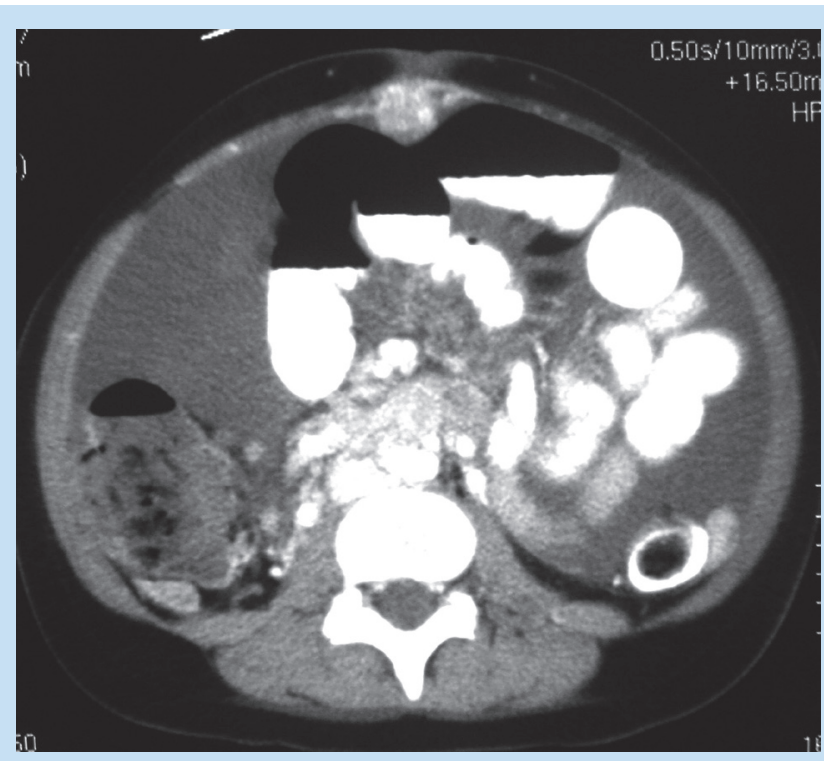

Fig. 1. Axial postcontrast CT of the abdomen - Sister Mary Joseph nodule. Also note the presence of subserosal and peritoneal metastases.

recurrence of a yolk sac tumour locally, and peritoneal, subserosal and liver metastases. Clinically an umbilical node was palpable.

1. Hill M, O’Leary JP. Sister Mary Joseph and her node. Am Surg 1996; 62: 328-329.

2. Gabriele R, Conte M, Egidi F, Borghese M. Umbilical metastases: current viewpoint. World I Surg Oncol 2005; $3: 13$.

3. Galvan VG. Sister Mary Joseph's nodule. Ann Intern Med 1998; 128: 410 .

was an excellent learning and sharing opportunity for all. Our thanks go to GE, with our hope that this was just an appetiser, with lots more to look forward to.

\section{Conference news}

The Neurological Association of South Africa (NASA) will be holding its annual 2007 congress at the Sandton Convention Centre from Wednesday 28 March to Saturday 31 March. This congress is being hosted by the Neurology Department of the University of the Witwatersrand under Prof. Girish Modi, and promises to be one of the better local congresses with at least eight international speakers; of special added interest to neuroradiology enthusiasts will be a series of neuroradiology lectures by Prof. Jonathan Kleefield.

Prof. Kleefield is an associate professor affiliated to Harvard Medical School. He has been a neuroradiologist since 1978, is the author or coauthor of numerous scientific publications and book chapters, and is a highly regarded teacher nationally and internationally.

This is not a congress any radiologist with an interest in neuroradiology will want to miss. A special rate will be negotiated for registrars, consultants in public service, and for sessional attendance. Please liase with your local NASA member for schedule details, etc., closer to the time. 